\title{
GPPS-CH-2020-0085
}

\section{Thermal Management System for More Electric Aircraft Avionics using Evaporative Spray Cooling}

Yogesh Thuraganur Venkategowda

MSc Thermal Power, Cranfield University

yogesh.thuraganur-venkategowda@cranfield.ac.uk

Cranfield, Buckinghamshire, UK

\author{
Soheil Jafari \\ Centre for Propulsion Engineering, Cranfield University \\ s.jafari@cranfield.ac.uk \\ Cranfield, Buckinghamshire, UK
}

\author{
Theoklis Nikolaidis \\ Centre for Propulsion Engineering, Cranfield University \\ t.nikolaidis@cranfield.ac.uk \\ Cranfield, Buckinghamshire, UK
}

\begin{abstract}
The aerospace industry is performing in today's market at a narrow margin in achieving system performance and operating costs. The avionics is consuming a decent amount of energy for electronic equipment which heats up and releases heat into the system. The effective cooling system is required to be designed for aero applications which play a major role in reducing weight and operating costs. Jet impingement has been an attractive cooling option in several industries over the past few decades. Over the years, jet impingement has been explored as a cooling option in microelectronics. The main purpose of this study is to explore the potential of the evaporative spray cooling method from a modelling perspective in more electric aircraft avionics, primarily from a heat transfer viewpoint. Boiling and evaporative liquid jets provide high heat transfer coefficients $(>20,000 \mathrm{~W} / \mathrm{m} 2 \mathrm{~K}$ ), which makes them attractive for electronic cooling applications. A zerodimensional methodological approach is proposed, and its effectiveness is confirmed via a sensitivity analysis of different coolants with variable Reynolds no. and heating plate diameter to nozzle diameter ratio on the designed system heat load dissipation capability.
\end{abstract}

\section{Nomenclature}

HTC Heat transfer coefficient

CHF Critical heat flux

LHV Latent heat of vaporisation

HFO Hydrofluoroolefins

\section{Abbreviations}

$\mathrm{Nu} \quad$ Nusselt no.

Re Reynolds no.

Pr Prandtl no.

Q Heat load

QC Convection heat load

$\mathrm{Q}_{\mathrm{CHF}}$ Heat load at CHF

QsuP Heat load at superheating

$q_{c} \quad$ Convective heat flux

$q_{\text {CHF }} \quad$ Critical heat flux

$\mathrm{T}_{\text {SAT }} \quad$ Saturated temperature

D Diameter of heating surface

d Diameter of nozzle

$\mathrm{S}_{\mathrm{NP}} \quad$ Space between nozzle and heating plate

$\mathrm{H}_{\mathrm{fg}} \quad$ Latent heat

\section{INTRODUCTION}

The evolution of technology development in aero propulsion from conventional to more electric dependency has shown way forward to achieve compact and light weight design of components. The additional requirement of more electric 
aircraft is to carry away the dissipated heat from the electronics, pneumatics, landing gears, and other avionics through compact thermal management system. The electronics consumes decent amount of energy and heats up the operating temperature beyond the operating range leads to mal functioning of control system. Jet impingement nucleate boiling phase change methodology is an attractive cooling choice to meet the purpose to achieve compact and light weight cooling system which handles heat flux up to $200 \mathrm{w} / \mathrm{cm}^{2}$ depending on the working fluid and saturated temperature. Over the past few decades, jet impingement has been explored as a cooling option in microelectronics and compact automobile applications. This paper covers the studies on thermal management system handling through jet impingement cooling in more electric avionics, primarily from a heat transfer aspect. Boiling and evaporative liquid jets achieves high heat transfer coefficients, which makes them attractive for electronic cooling applications [2]. Typically, nucleate boiling is the preferred regime of operation due to a small increase in wall superheat is accompanied by a large increase in wall heat flux dissipation. Also, in electronics, it may not be possible to afford very large temperature differences between solid and liquid surface, a characteristic essential for regimes such as film boiling. In the context of boiling liquid jets, extensive work has already reported in many literatures. With reference to publicly available literature, sensitive studies which affect the thermal heat transfer coefficients are carried out through various parameters like nozzle diameter, jet velocity, impinging space between nozzle and heating surface, cooling fluid and mass flow rates.

The natural and forced cooling application and its effectiveness are highlighted for motor vehicle applications through numerical simulations and these are compared with evaporative boiling phase cooling mechanism. The outcome of the studies from Jafari et al [1] concludes the vapour bubble formation at solid-liquid interaction separates it from the process of evaporation at liquid-vapour boundary. The boiling jet impingement studies to cool high power electronics are shown on unit area of heat source and developed non-dimensional heat transfer relation through sensitivity parameters like nozzle diameter, nozzle to source surface spacing, jet velocity. Etc, through numerical simulation by Narumanchi et al [2]. A phenomenal heat transfer performance due to vapour bubble formation during phase change explained by Qui et al [3]. The influence of heat transfer through nozzle to plate spacing, which affects the Nusselt no. is explained by Choo et al [5]. Mukerjee and Dhir [7] presented the use of numerical simulations to show the bubble formation during boiling. The different HTC mechanism shows the bubble merger process over the wall through transient conduction and convection, the results validated with experiments. Miyasaka et al. [9] explained the critical heat flux and subcooled nucleate boiling in the transient region between a two-dimensional water jet and a heated surface. The paper covered the transient region through experimental results and concerns the effect of subcooling, jet velocity, and stagnation pressure on critical heat flux and nucleate boiling. Whyatt and Chic [10] reported the power consumption from more Electric Aircraft using Solid Oxide Fuel Cell. The report gives the close estimation of electric power consumption by typical more electric Boeing 787 aircraft.

The paper will explore the potential of spray cooling mechanism for dealing with thermal loads in avionics of more electric aircraft. Both sub-boiling single phase and two-phase nucleate cooling will be considered through a systematic zero-dimensional approach. The sensitivity analysis of different coolant, with variable Reynolds no. and D/d (Heating plate diameter to nozzle diameter) ratio on the heat load dissipation capability of the proposed mechanism is presented.

\section{Boiling and Nucleate Heat Transfer}

The heating surface dissipates heat energy into liquid which is in contact with surface leads to the formation of vapour bubbles due to the nucleation heat transfer process. The influence of phase change depends on the surface conditions like roughness, aging, and positioning of the nozzle to impinge boiling fluid over the surface. Figure 1 shows the heat transfer effectiveness at different regimes of the single-phase boiling and two-phase nucleate boiling zone to achieve the maximum heat flux [2]. The study focusses on the estimation of single-phase convection heat transfer and phase change nucleate boiling to estimate the overall heat flux. Figure 2 shows the typical Nucleate boiling closed refrigeration circuit for the application of avionics electronic cooling. The suitable refrigerant at close to boiling temperature is injected through a nozzle positioned at distance $S$ from the heating surface. The liquid in contact with heated surface evaporates to vapour when it attains saturated temperature. The exit vapour is pressurised in compressor which further increases its temperature at exit, the heated vapour will be passed through condenser to dissipate heat and liquify in heat exchanger later collects in receiver, the cooling liquid is available for jet impingement which continues in the closed loop cooling cycle. The injection mass flow control based on the heat loading and surface temperature rise. 


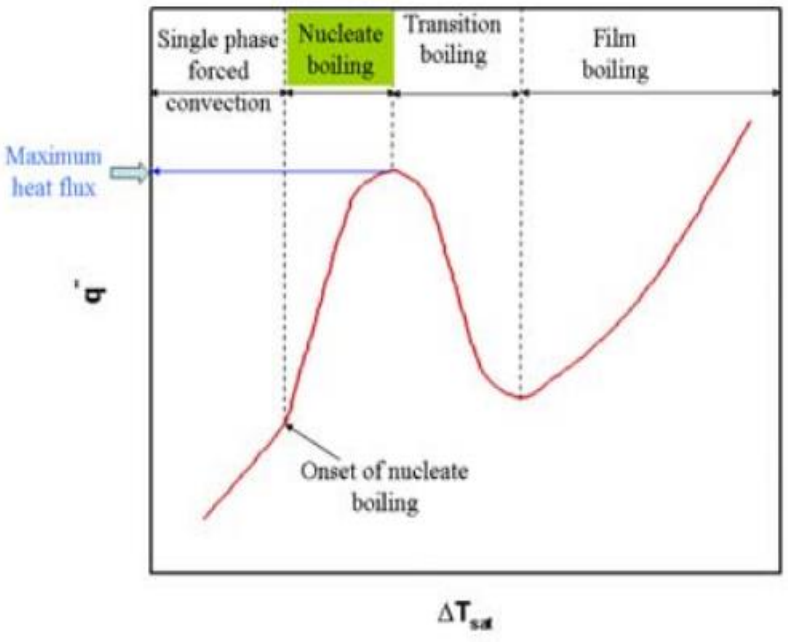

Figure 1 General boiling curve for saturated liquids [2]

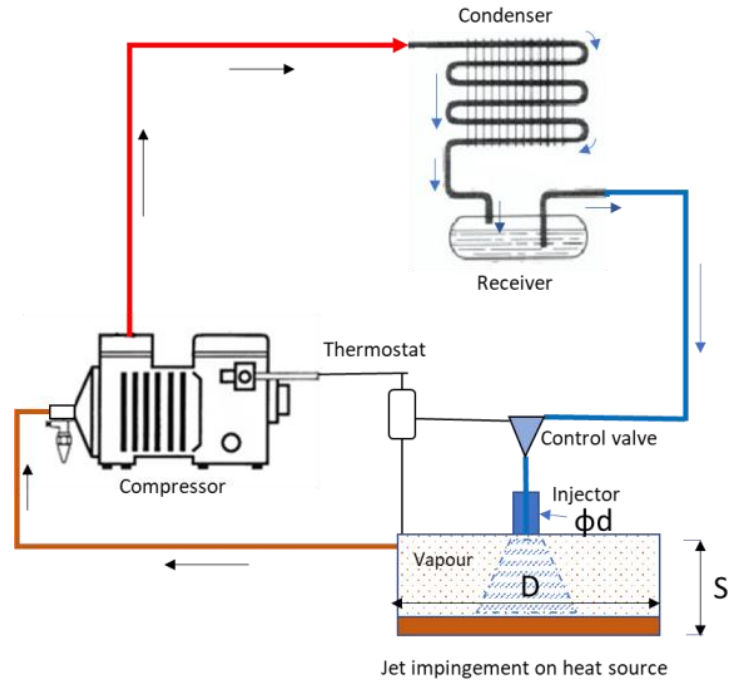

Figure 2 Cooling circuit diagram with injector (jet nozzle)

\section{BOEING 787 MORE ELECTRIC POWER LOAD}

The power consumption by more electric aircraft is more than any conventional aircraft due to its propulsion, landing gears and wings controls are by stored electric power. The electric power load of the Boeing 787 at different flight conditions is shown in figure 3 [10]. The maximum load as reported is during climb at forty thousand feet altitude, hence the worst condition is the point of reference to estimate the design requirements of the cooling system.

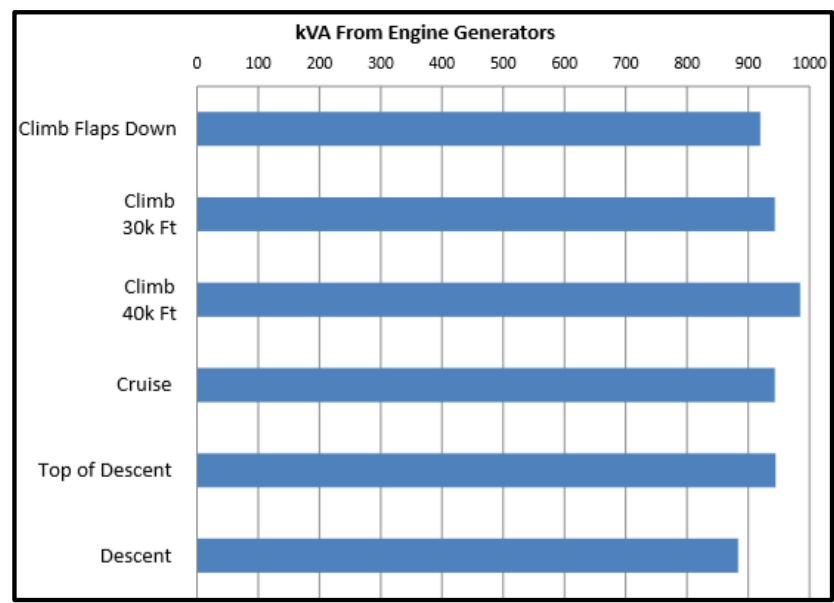

Figure 3 power load of more electric 787 engine at different flight conditions [10]

\section{HEAT SINK DESIGN FLOW CHART}

The design of the heat sink to meet the variable heat load will follow the steps as shown in flow chart figure 4 . Generally, the heat load will be varying in nature in most of the cases, even for more electric avionics the heat load varies based on the flight envelope (Figure 3). During landing and take-off most of the pneumatic controls along with electronics must work to satisfy the mechanical and control requirements of the system and during cruise where only electronics will operate with minimum power requirement. Hence the block diagram focused on meeting the variable cooling requirement by controlling mass flow rate which influences heat transfer through forced convection (sub-boiling cooling) and nucleate boiling (vaporisation). However, further heat flux can be enhanced as the vapour is superheated beyond the saturated temperature. 


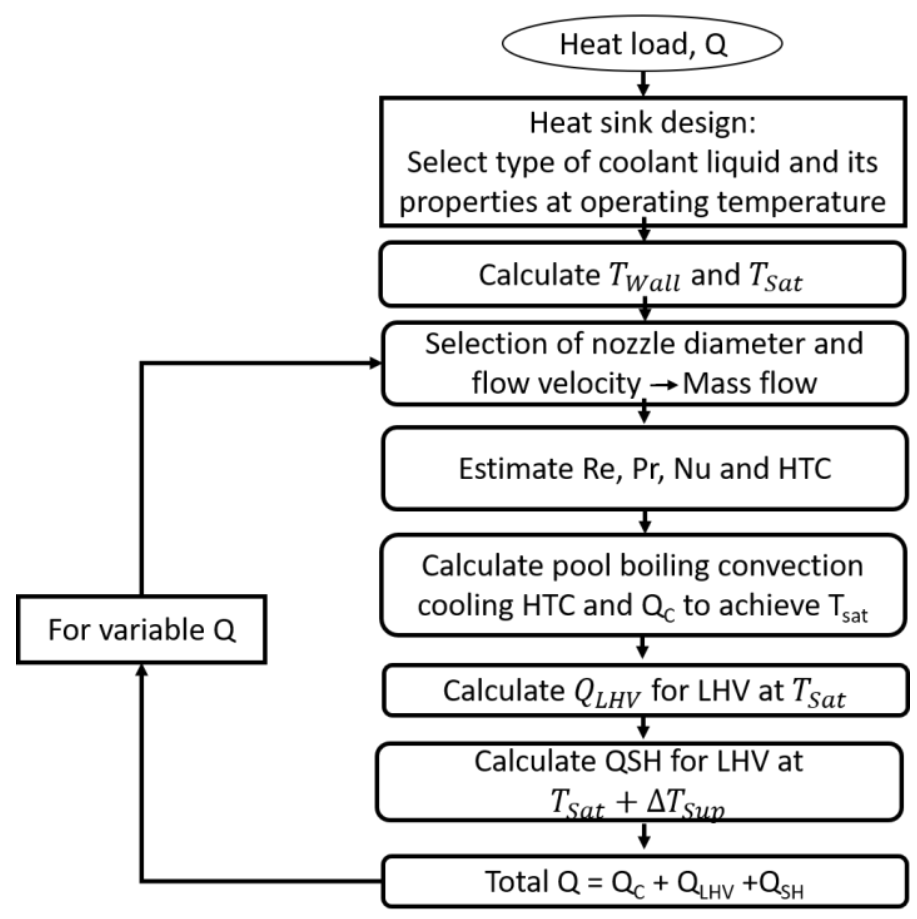

Figure 4 Flow chart of to meet the heat sink cooling requirement

\section{SUB-BOILING COOLING}

A zero-dimensional (0-D) analysis is presented in this section for calculations of heat transfer at single-phase boiling and two-phase nucleate boiling stages, the estimation of heat load and convective heat transfer to water at liquid phase. The change in phase to vapour is discussed under nucleate boiling relations.

\section{Convective heat transfer}

$$
\begin{aligned}
& Q_{C}=C A\left(T_{\text {Sat }}-T_{l}\right)^{m} \\
& C=x h_{l}
\end{aligned}
$$

Where $\mathrm{x}$ and $\mathrm{m}$ are the coefficients determined from experimental studies.

\section{Latent heat evaporation}

$$
Q_{L H V}=H_{f g} m_{l}
$$

\section{Heat absorbed for superheating vapour}

$$
Q_{s}=h_{v} A\left(T_{v}-T_{\text {sat }}\right)
$$

\section{Total heat flux absorbed}

$$
Q=Q_{C}+Q_{L H V}+Q_{S}
$$

The calculation is shown for different coolant with different heat loads, the data compared with the reference and experimental results [2].

Estimating HTC for any thermal applications is considered as most challenging in the process of designing cooling systems. Based on the references and experimental studies carried out by various scholars the relations for convection heat transfer are deduced through non-dimensional numbers. Some of their experimental work in establishing a relation of HTC for boiling phase application are listed below based on the inlet parameters to match the various Reynolds no. and Prandtl number. The Nusselt number relation is shown for variable Reynolds no. and nozzle-to-heating plate ratios.

Martin correlation [14] for a single circular submerged jet

$$
\frac{N u}{P r^{0.42}}=G\left(\frac{d}{R}, \frac{S_{N P}}{d}\right) F\left(R e_{J}\right)
$$




$$
\begin{aligned}
& G\left(\frac{d}{R}, \frac{S_{N P}}{d}\right)=\frac{d}{R}\left\{\frac{1-\frac{1.1 d}{R}}{1+\frac{0.1\left(\frac{S_{N P}}{d}-6\right) d}{R}}\right\} \\
& F\left(R e_{J}\right)=2 R e_{J}^{\frac{1}{2}}\left(1+\frac{R e_{J}^{0.55}}{200}\right)^{0.5}
\end{aligned}
$$

$2,000 \leq \operatorname{Re}_{\mathrm{J}} \leq 400,000 ; 2.5 \leq \mathrm{R} / \mathrm{d} \leq 7.5 ; 2 \leq \mathrm{S}_{\mathrm{NP}} / \mathrm{d} \leq 12$

Where, $\mathrm{d}=$ nozzle diameter, $\mathrm{S}_{\mathrm{NP}}=$ nozzle-to-target separation, $\mathrm{R}=$ equivalent radius of the target, $N u=h_{a v g} d / K$, $R e_{J}=\rho V d / \mu$, and $\operatorname{Pr}=\mu C_{p} / K$

Womac et al. correlation [13] for a single circular submerged jet. This correlation is for the same jet configuration as the Martin correlation [14] presented previously.

$$
\begin{aligned}
& \frac{N u_{l}}{P r^{0.4}}=C_{1} R e_{d}^{m} \frac{l}{d} A_{r}+C_{2} R e_{L}^{n} \frac{l}{L}\left(1-A_{r}\right) \\
& L=\frac{(0.5 \sqrt{2} l-1.9 d)+(0.5 l-1.9 d)}{2} \\
& A_{r}=\pi(1.9 d)^{2} / l^{2}
\end{aligned}
$$

$R e_{d}<50000 ; 1.65 \leq \mathrm{d} \leq 6.55 \mathrm{~mm} ; 1.5 \leq \mathrm{SNP} / \mathrm{d} \leq 4$

Where, $d=$ nozzle diameter, $S_{N P}=$ nozzle-to-target separation, $l=$ length of the side of the square heat source, $L=$ average length of the wall jet region, $l=12.7 \mathrm{~mm}, m=0.5, n=0.8, C 1=0.785, C 2=0.0257, N u_{l}=h_{a v g} l / K, R e_{L}=$ $\rho V d / \mu$, and $\operatorname{Pr}=\mu C_{p} / K$.

Garimella and Rice [15] correlation for a single confined circular submerged jet

$$
\begin{aligned}
& N u=0.160 \operatorname{Re}^{0.695} \operatorname{Pr}^{0.4}\left(\frac{S_{N F}}{d}\right)^{-0.11}\left(\frac{l_{N}}{d}\right)^{-0.11} \\
& 1.59 \leq d \leq 6.35 m m ; 4000 \leq R e \leq 23000 ; 1 \leq \frac{S_{N P}}{d} \leq 5 ; 0.25 \leq l_{N} / d \leq 12 \\
& N u=0.164 \operatorname{Re}^{0.772} \operatorname{Pr}^{0.4}\left(\frac{S_{N F}}{d}\right)^{-0.52}\left(\frac{l_{N}}{d}\right)^{-0.05}
\end{aligned}
$$

Variable parameter range remain same as above, except $6 \leq S_{N P} / d \leq 14$

Where, $d=$ nozzle diameter, $S_{N P}=$ nozzle-to-target separation, $l_{N}=$ length of the nozzle, $N u=h_{\text {avg }} d / K, \operatorname{Re}=\rho V d / \mu$, and $\operatorname{Pr}=\mu C_{p} / K$.

Womac et al. correlation [13] for a single circular free-surface jet

$$
\begin{aligned}
& \frac{N u_{l}}{\operatorname{Pr}^{0.4}}=C_{1} R e_{d i}^{m} \frac{l}{d_{i}} A_{r}+C_{2} \operatorname{Re}_{L}^{n} \frac{l}{L}\left(1-A_{r}\right) \\
& L=\frac{\left(0.5 \sqrt{2} l-d_{i}\right)+\left(0.5 l-d_{i}\right)}{2} \\
& A_{r}=\pi\left(d_{i}\right)^{2} / l^{2} \\
& R e_{d i}<50000 ; 1.65 \leq d \leq 6.66 \mathrm{~mm} ; 3.5 \leq \frac{s_{N P}}{d} \leq 10
\end{aligned}
$$

Where, $d=$ nozzle diameter, $d_{i}=$ jet diameter in impingement plane, $S_{N P}=$ nozzle-to-target separation, $l=$ length of the side of the square heat source, $L=$ average length of the wall jet region, $l=12.7 \mathrm{~mm}, m=0.5, n=0.532, C 1=0.516$, $C 2=0.491, N u=h_{\text {avg }} d / K, \operatorname{Re}=\rho V d / \mu$, and $\operatorname{Pr}=\mu C_{p} / K$.

Martin correlation [14] for multiple circular submerged jets

$$
\begin{aligned}
& {\left[\frac{N u}{P r^{0.42}}\right]_{A N}=K\left(\frac{S_{N P}}{d}, a_{J}\right) G\left(\frac{s_{N P}}{d}, a_{2}\right) F\left(R e_{2}\right)_{A N}} \\
& K\left(\frac{S_{N P}}{d}, a_{J}\right)=\left[1+\left(\frac{s_{N P} / d}{0.6 / \sqrt{a_{J}}}\right)^{6}\right]^{-0.05}
\end{aligned}
$$




$$
\begin{aligned}
& G\left(\frac{S_{N P}}{d}, a_{J}\right)=\frac{2 \sqrt{a_{J}}\left(1-2.2 \sqrt{a_{J}}\right)}{1+0.2\left(S_{N P} / d-6\right) \sqrt{a_{J}}} \\
& F\left(R e_{J}\right)_{A N}=0.5 R e_{J}^{2 / 3} \\
& 2000 \leq R e_{J} \leq 100000 ; 0.004 \leq a_{J} \leq 0.04 ; 2 \leq S_{N P} / d \leq 12
\end{aligned}
$$

The critical heating factor shows the dependency design parameters, the relation shows a close match with experimental data [2].

\section{NUCLEATE BOILING}

Critical heat flux, where the wall temperature shoots up due to dry out conditions in which no liquid is available to sustain boiling. Nucleate boiling is the formation of bubble motion and mixing; hence it is a strong process that does not depend on many jet parameters, unlike single-phase jets. Some of the scholars have done an enormous amount of work to draw the relation between non-dimensional numbers at this dried out conditions.

a. Monde et al. [16 -19],

$$
q_{C H F} / \rho_{v} h_{f g} u=0.221\left(\frac{\rho_{l}}{\rho_{v}}\right)^{0.645}\left(\frac{2 \sigma}{\rho_{l} u^{2}(D-d)}\right)^{0.343}\left(1+\frac{D}{d}\right)^{-0.364}\left(1+\varepsilon_{s u b}\right)
$$

\section{b. Katto and Yokoya [20]}

$$
\begin{aligned}
& \frac{q_{C H F}}{\rho_{l} h_{f g} u}=K\left(\frac{\sigma}{\rho_{l} u^{2}(D-d)}\right)^{m}\left(1+\frac{D}{d}\right)^{-m} \\
& K=0.0166+7.0\left(\frac{\rho_{l}}{\rho_{v}}\right)^{-1.12} \\
& m=0.374\left(\frac{\rho_{v}}{\rho_{l}}\right)^{0.0155} \text { for } \frac{\rho_{v}}{\rho_{l}} \leq 0.00403 \\
& m=0.532\left(\frac{\rho_{v}}{\rho_{l}}\right)^{0.0794} \text { for } \frac{\rho_{v}}{\rho_{l}} \geq 0.00403
\end{aligned}
$$

\section{c. Sharan and Lienhard [21]}

$$
\begin{aligned}
& \frac{q_{C H F}}{\rho_{v} h_{f g} u}=f(r)\left(\frac{D}{d}\right)^{-0.33}\left(\frac{1000 \sigma}{\rho_{l} u^{2} D}\right)^{A(r)} ; r=\frac{\rho_{l}}{\rho_{v}} \\
& f(r)=0.21+0.00171 r \\
& A(r)=0.486+0.06052 \ln r-0.0378(\ln r)^{2}+0.00362(\ln r)^{3}
\end{aligned}
$$

Where, $q_{C H F}$ is the CHF, $h_{f g}$ is the latent heat, $u$ is the liquid velocity, $\rho_{l}$ is the liquid density, $\rho_{v}$ is the vapor density, $\varepsilon_{\text {Sub }}$ is a cooling parameter, $D$ is the effective target diameter corresponding to one jet, $d$ is the jet diameter, and $f$ and $A$ are functions [21].

The correlation presented by Monde et al. and Katto and Yokoya are based on nondimensional numbers, while the CHF correlation presented by Sharan and Lienhard is based on the mechanical energy stability criterion. The results are estimated from above models and compared with different working fluid and is shown in figure 4 and in the results section, the results are explored to obtain from these correlations for sub-boiling heat transfer and nucleate boiling through CHF.

\section{RESULTS AND DISCUSSIONS}

The calculations for the design of a typical heat sink with jet impingement is carried out using the above nondimensional relations. Since the convection heating depends on variable heat load with Reynolds number, Martin correlation relation covers the wide range of Reynolds number from 2000 to 400,000, hence the sub-boiling (singe-phase) cooling estimation is carried out and presented. Figure 6 shows the heat flux estimated through convection using Martin correlation at sub cooling liquid phase with sub cooling temperature of $3^{\circ} \mathrm{C}$ from saturated temperature and compared with Reynolds number corresponding to nozzle condition. The increase in Re no. proportional to mass flow change. Hence, tends to increase the heat flux for different working fluids.

Monde et al. non-dimensional correlation is compared with models of Katto \& Yokoya and Sharan \& Lienhard for water, R113 and HFO as working fluids. Figure 6 shows the comparison of models where water as working fluid estimates the similar heat flux for all three models, whereas R113 and HFO predicts almost similar value from Katto \& Yokoya and Sharan \& Lienhard models, while Monde et al predicts different value with corresponding working fluids. The Monde et 
al model is simplified model where it does not relate diameter of the nozzle and heating surface area and it is insufficient to predict critical heat flux [20]. Katto \& Yokoya model brought out correction factor to estimate CHF based on the experimental studies carried out on different working fluids. The experimental relation for the vapour and liquid density ratio of 0.000624 [20] is shown in figure 5 and the results estimated for the designed model for jet impingement cooling is compared with water as working fluid, the results are in close agreement with experiments. The CHF estimated for three fluids are based on Katto \& Yokoya model.

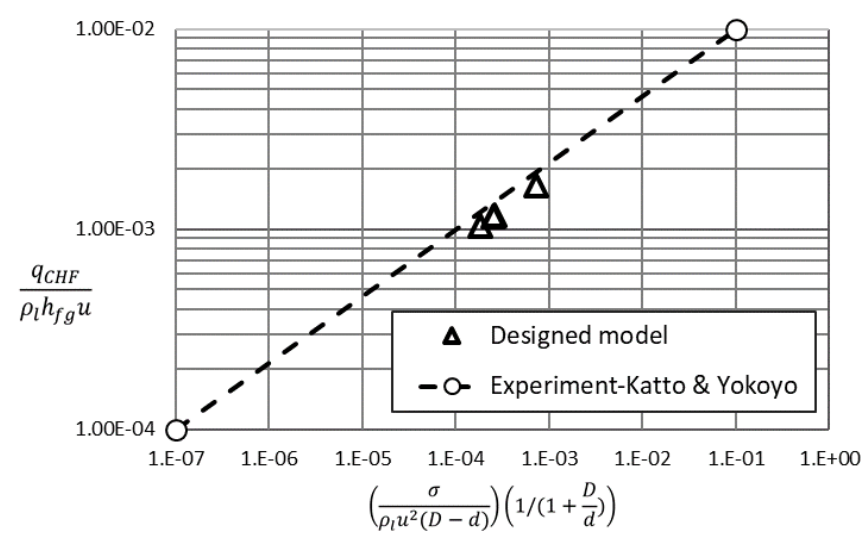

Figure 5: Validation of designed model with experimental result of Katto \& Yokoyo [20]

Figure 7 shows the CHF of three working fluids compared with heating surface and nozzle dia. ratio, figure 8 shows the heat flux and nozzle inlet Re no. relation with working fluids, all fluids shows the tendency of increasing with heat flux. Hydrofluoroolefins (HFO) is an unstructured organic compound of hydrogen, fluorine, and carbon. It has zero depletion potential of the ozone layer; hence it is more suitable for aero applications. Figure 9 shows the CHF of HFO fluid with nozzle diameter at different velocity, the relation is useful for proper estimation of refrigerant flow rate to set the operating temperature requirements.

The critical heat flux (nucleate boiling phase) heat transfer increases the cooling rate enormously comparing with convection heat transfer. Figure 10 shows the heat flux at convection and CHF nucleate phase change for HFO and R113 refrigerants, which accounts CHF heat transfer is more by at least three times of convection cooling. Hence the jet impingement phase change cooling helps in achieving compact design and less operational cost.

The total power load of more electric aircraft is discussed with reference to figure 3 , the variation in power at different flight modes demands the fluctuation to supply refrigerant for cooling in jet impingement system, Figure 11 shows the coolant flow rate required based on the heat load on the power requirement of the Boeing 787 engine. Since HFO is more suitable refrigerant for avionics application, the mass flow required to be pumped is estimated, however the combination of parameters like nozzle diameter, velocity of fluid, refrigerant properties can be suitably selected to optimise the cooling system design.

The overall studies carried out for unit area to establish heat transfer limits, the cooling requirement estimated above based on considering full heat load under jet impingement cooling, which is may not be the case. The electronics architecture of avionics and actual heat for dissipation through jet impingement to be studied to achieve the optimised cooling system design.

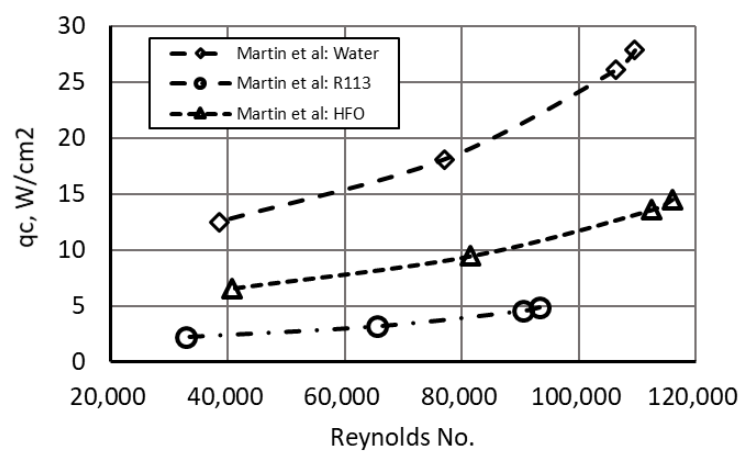

Figure 6: Heat flux through convection by working fluids

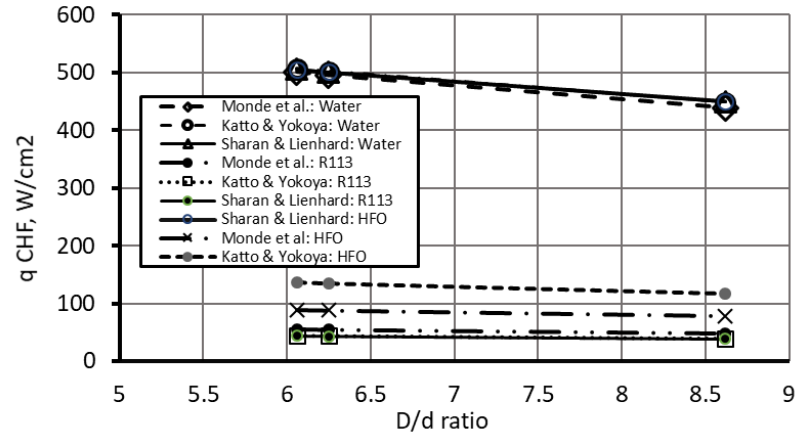

Figure 7: Critical heat flux with $d / D$ ratio relation with different CHF models 


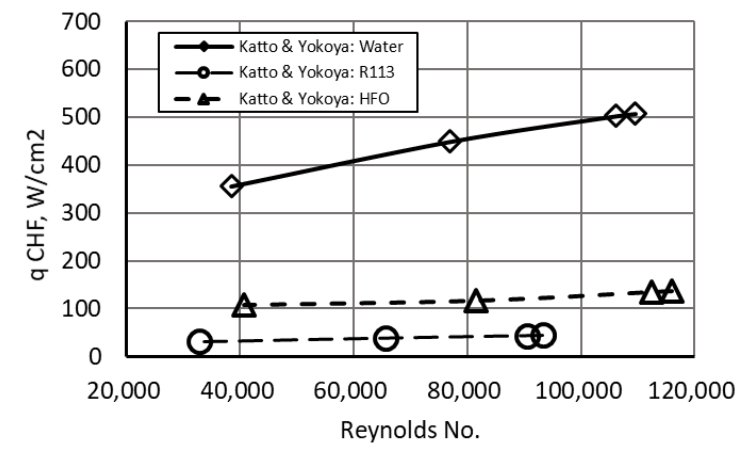

Figure 8: Critical Heat flux with Re No. by Katto \& Yokoya model

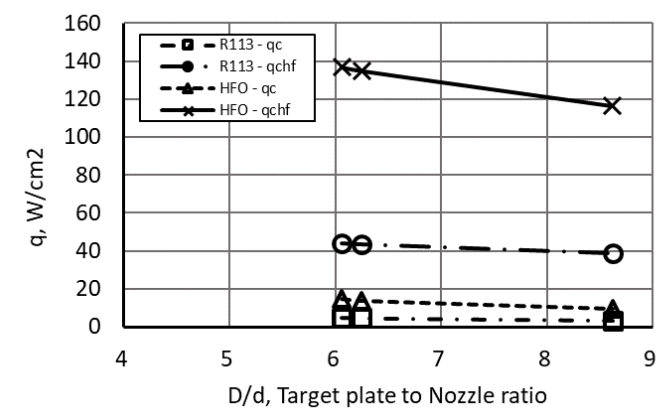

\section{Figure 10: Convective \& Critical heat flux with D/d ratio of $R 113$ and HFO}

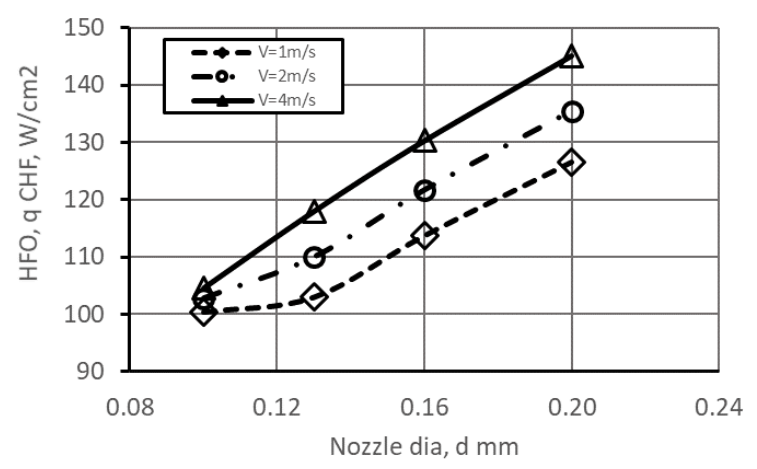

Figure 9: CHF at varying velocity for HFO

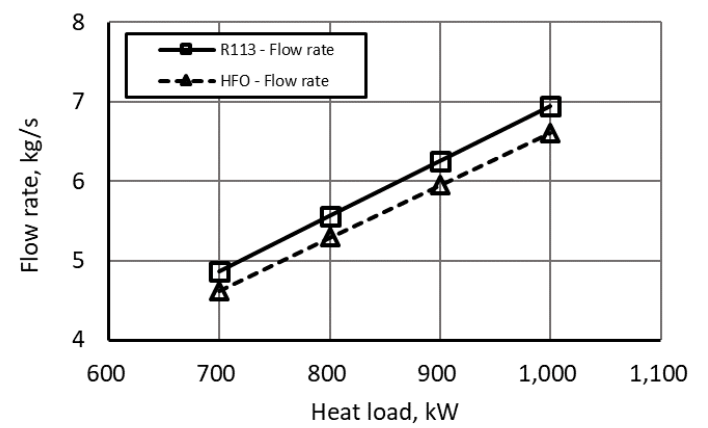

Figure 11: Coolant flow rate for variable heat load

\section{CONCLUSION}

Non-dimensional correlations to predict heat flux of sub-cooling and nucleate boiling is more reasonable to design the cooling system for Avionics applications, where efficiency, environmentally friendly, and weight are major concerns. The heat flux relation of designed model using zero dimensional relations are compared with experimental studies carried out by Katto \& Yokoyo and found results are in close agreement. The sensitivity studies carried out on HFO and R113 refrigerants show the effective nucleate cooling system can be obtained by considering the parameters like nozzle diameter, the spacing between nozzle and heating surface, heating surface area, velocity of the flow and densities of liquid and vapour. This paper explored the characteristics of HFO hinting for further studies on Avionics applications. Phase change nucleate boiling heat flux is more than three times compared with single-phase boiling; hence heat transfer rate can be achieved jet impingement phase change cooling in a compact system.

\section{REFERENCES}

1. Jafari, S. et al. (2017) 'A review of evaporative cooling system concepts for engine thermal management in motor vehicles', Proceedings of the Institution of Mechanical Engineers, Part D: Journal of Automobile Engineering, 231(8), pp. 1126-1143. doi: 10.1177/0954407016674606.

2. Narumanchi, S. V. J., Hassani, V. and Bharathan, D. (2005) 'Modeling Single-Phase and Boiling Liquid Jet Impingement Cooling in Power Electronics', (December). doi: 10.2172/861486.

3. Ma, C. F., \& Bergles, A. E. (1986). Jet impingement nucleate boiling. International Journal of Heat and Mass Transfer, 29(8), 1095-1101. https://doi.org/10.1016/0017-9310(86)90140-7

4. Qiu, L., Dubey, S., Choo, F. H., \& Duan, F. (2015). Recent developments of jet impingement nucleate boiling. International Journal of Heat and Mass Transfer, 89, 42-58. https://doi.org/10.1016/j.ijheatmasstransfer.2015.05.025

5. Choo, K. et al. (2016) 'The influence of nozzle-to-plate spacing on heat transfer and fluid flow of submerged jet impingement', International Journal of Heat and Mass Transfer. Elsevier Ltd, 97, pp. 66-69. doi: 10.1016/j.ijheatmasstransfer.2016.01.060.

6. Nobari, A. H., Prodanovic, V. and Militzer, M. (2016) 'Heat transfer of a stationary steel plate during water jet impingement cooling', International Journal of Heat and Mass Transfer. Elsevier Ltd, 101, pp. 1138-1150. doi: 10.1016/j.ijheatmasstransfer.2016.05.108.

7. Mukherjee, A. and Dhir, V. K. (2004) 'Study of lateral merger of vapor bubbles during nucleate pool boiling', Journal of Heat Transfer, 126(6), pp. 1023-1039. doi: 10.1115/1.1834614. 
8. Le Martelot, S., Saurel, R. and Nkonga, B. (2014) 'Towards the direct numerical simulation of nucleate boiling flows', International Journal of Multiphase Flow. Elsevier Ltd, 66, pp. 62-78. doi: 10.1016/j.ijmultiphaseflow.2014.06.010.

9. Miyasaka, Y., Inada, S. and Owase, Y. (1980) 'Critical heat flux and subcooled nucleate boiling in transient region between a two-dimensional water jet and a heated surface', Journal of Chemical Engineering of Japan, 13(1), pp. 29. 35. doi: 10.1252/jcej.13.29.

10. Whyatt, G. A. and Chick, L. A. (2012) 'Electrical Generation for More-Electric Aircraft Using Solid Oxide Fuel Cells', Prepared for the U.S. Department of Energy under Contract DE-AC05-76RL01830, p. 110. doi: 10.2172/1056768.

11. Langari, M. et al. (2018) 'Multiphase computational fluid dynamics-conjugate heat transfer for spray cooling in the non-boiling regime', Journal of Computational Multiphase Flows, 10(1), pp. 33-42. doi: 10.1177/1757482X17746921.

12. Fadhl, B., Wrobel, L. C. and Jouhara, H. (2013) 'Numerical modelling of the temperature distribution in a two-phase closed thermosyphon', Applied Thermal Engineering, 60(1-2), pp. 122-131. doi: 10.1016/j.applthermaleng.2013.06.044.

13. Womac, D.J, Ramadhyani, S and Incropera, F.P, (1993) 'Correlating equations for impingement cooling of small heat sources with single circular liquid jets', ASME Journal of Heat Transfer, 115, pp. 106-115

14. Martin, H, (1977) 'Heat and mass transfer between impinging gas jets and solid surfaces', Advances in heat transfer, 13 , pp. 1-60

15. Garimella, S.V and Rice, R.A., (1995) 'Confined and submerged liquid jet impingement heat transfer', ASME Journal of Heat Transfer, 117, pp. 871-877.

16. Monde, M. and Katto, Y., (1978), 'Burnout in a high heat-flux boiling system with an impinging jet', Int. Journal on Heat Mass Transfer, 21, pp. 295-305

17. Monde, M. and Mitsutake, Y., (1996), 'Critical heat flux in forced convective subcooled boiling with multiple impinging jets', ASME Journal of Heat Transfer, 117, pp. 241-243

18. Monde, M. (1987), 'Critical heat flux in saturated forced convective boiling on a heated disk with an impinging jet', ASME Journal of Heat Transfer, 109, pp. 991-996.

19. Monde, M. and Inoue, T (1991), 'Critical heat flux in saturated forced convective boiling on a heated disk with multiple impinging jets', ASME Journal of Heat Transfer, 113, pp. 722-727.

20. Katto, Y. and Yokoya, S., (1988), 'Critical heat flux on a disk heater cooled by a circular of saturated liquid impinging at the centre, International Journal on Heat Mass Transfer, 31(2), pp. 219-227.

21. Sharan, A and Lienhard, (1985), 'On predicting burnout in the jet-disk configuration', ASME Journal of Heat Transfer, 107, pp. 398-401. 